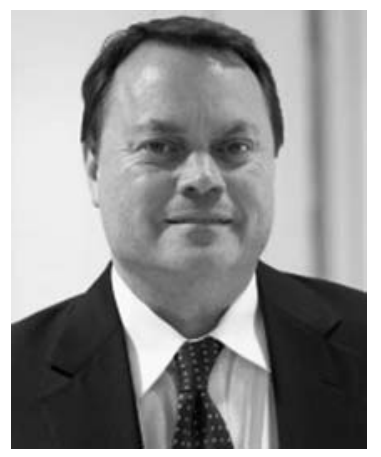

\title{
A Conversation with David Lyden
}

\author{
Interviewer: Paula Kiberstis \\ Senior Editor, Science
}

David Lyden is the Stavros S. Niarchos Professor in Pediatrics and Cell and Developmental Biology at Weill Cornell Medicine.

Paula Kiberstis: Your expertise is in metastasis, which is the process by which primary tumor cells journey to a distant site and start growing. Most cancer patients die of metastases, and if we understand how it occurs, we might be able to prevent it or treat it. How did you get into this field?

Dr. Lyden: We focus on translational research in my lab, so that means our investigations start with patient data, then we bring this information for further studies back to the laboratory or the bench. I'm a pediatric neuro-oncologist by training. Although the cancer rate is very low in children compared with adults $(10 \%$ of all cancers are in children younger than 18 years), what's really significant is that metastasis is very highly noted in all the pediatric cancers, and they have a short latency period for disease progression. That means that when they're diagnosed, if you don't treat the pediatric patient right away, they'll develop metastases very quickly. This is in stark contrast to some adult cancers, such as colon or prostate cancer, where the metastases take years to develop. As a pediatric oncologist, I've a golden opportunity to understand the evolution of the whole metastatic process by using my patients as examples and testing some of the pediatric cancers in the laboratory.

Paula Kiberstis: Metastasis doesn't seem to be a random process. There are certain tumors that prefer to metastasize to certain sites. Prostate cancer will metastasize to bone and liver, whereas pancreatic cancer never metastasizes to bone. One of the central players appears to be a little membrane vesicle called an exosome. Could you tell us about that?

Dr. Lyden: One of the biggest mysteries in cancer is why it spreads to certain organ sites. Pediatric cancers, adult cancers, they all go to certain organ sites, and much of the process was thought to be based on the tumor cell dictating all the steps: The tumor cell leaves the primary tumor, enters the bloodstream, exits the bloodstream, and then dictates its future site, but that seemed too simplified to me.

Cancer is clearly a systemic disease. If you see a cancer patient who's newly diagnosed, there are a lot of complications. They could have clotting, they could have loss of muscle, which we call cachexia; there are a lot of systemic problems. How does the cancer communicate with the body? Originally, I thought it was just soluble growth factors, but when we studied early metastases in our laboratory, we noticed a conditioned microenvironment, a premetastatic niche, at the future sites of the metastases. Even before the tumor gets there, changes are taking place at these organs, making them favorable sites for metastases. We noticed bone marrow-derived progenitor cells clustering in the lung, and extracellular matrix-like scar tissue with collagen deposits, and together they were forming this microenvironment. We noticed that it occurred at the exact site where tumor cells were landing, like a landing pad for metastasis formation. When we studied this site by electron microscopy, we found these bubble-like bodies the size of viruses but they were labeled identically to the original tumor. They were tumor-derived vesicles that we now know as exosomes.

Paula Kiberstis: Do you know what's inside them?

Dr. Lyden: Pretty much whatever we see in cells can be packaged in exosomes: DNA, RNA, and proteins. A cancer patient is secreting billions of exosomes into the bloodstream that package tumor proteins, RNA, and DNA as carriers of tumor information. If they're able to fuse with cells at distant sites and pass on tumor information to normal, healthy cells, that's detrimental to the patient.

Paula Kiberstis: Is there specificity as to how the vesicle finds its way to the organ? Is there something on the outside or within the membrane that helps it get to the right place?

(C) 2016 Lyden. This article is distributed under the terms of the Creative Commons Attribution-NonCommercial License, which permits reuse and redistribution, except for commercial purposes, provided that the original author and source are credited. 
Dr. Lyden: Our laboratory was one of the first to do a protein characterization of adhesion molecules, which stick out from the exosome like antennae. We found a 24-member protein family called integrins. Which member or members of the integrin family is present on exosomes dictates which organ (and which cells in the organ) the exosomes will fuse with. Different integrins explain why some tumor exosomes go to the liver versus the lung versus the brain. This is a start to explaining why cancer spreads to certain organs.

Paula Kiberstis: You pointed out that MET, which is a tyrosine kinase, was within the vesicle. How does that help the tumor cell grow?

Dr. Lyden: The MET oncoprotein is actually the product of an oncogene. When overactive, such a protein promotes cancer growth and spread. Oncoproteins are packaged in exosomes secreted by tumor cells and can be transferred to normal cells, altering their function. C-MET oncoprotein can promote blood vessel development, growth, and migration, and that's exactly what we saw. When that MET protein was transferred, say, to bone marrow cells, we saw migration and survival properties that brought these abnormal bone marrow cells to this premetastatic microenvironment supporting metastases. Basically, it can help transform normal cells at distant sites.

Paula Kiberstis: Is the communication two-way or is it unidirectional from the tumor?

Dr. Lyden: That's a good question. There are other laboratories studying the exosomes in different cell types. Immune and blood vessel cells in your body can also secrete exosomes. They can be normal, but in the cancer environment they can actually give abnormal information back to the tumor and make the tumor grow even faster. We have tumor exosomes going in one direction and all your body's exosomes going back to the tumor, so it's actually a very complex exchange of information.

Paula Kiberstis: What about clinical applications? Where do you see the future for early detection or for using this information to develop a therapy?

Dr. Lyden: There's a lot of potential for studying exosomes and helping clinicians to determine the clinical outcome of a patient. For example, if you have colon cancer and you have a CT scan of your liver, and there's no metastasis in the liver, the surgeon will take out the primary tumor, but we know that $20 \%$ of these patients will develop liver metastases in the future. Basically, everyone who has the surgery is sent home, and when those $20 \%$ of the patients develop liver metastases, they then go on to the oncologist who will start an aggressive therapy.

Can we do a better job? Can we help predict which patients are in trouble right from the beginning, so you can initiate advancing therapeutics from an early start and prevent metastases? We're hoping we can take a blood sample and collect the exosomes from the plasma by centrifugation. It's complicated by the fact that exosomes occur normally in the body; they're mostly from bone marrow cells. Nevertheless, tumor exosomes are very distinct. If we could recognize them and analyze their protein content and determine if some of the protein signatures are more supportive of metastases, we could make a big impact in how we treat our patients.

If tumor exosomes are missing integrins, they're unlikely to fuse with organs, but the more integrins that you have expressed on the exosomes, the more likely they are to stick to multiple organs. It's not that uncommon to see a lung cancer patient who might have metastases to 10 different organs with up to 15 different integrins expressed on that exosome. We find the more integrins on the exosome surface you have, the worse the prognosis. 


\section{$\$_{\text {CSH\& }}^{\infty}$ Cold Spring Harbor Symposia SYMPOSIA}

\section{A Conversation with David Lyden}

Cold Spring Harb Symp Quant Biol 2016 81: 326-327 originally published online April 19, 2017 Access the most recent version at doi:10.1101/sqb.2016.81.032110

Creative This article is distributed under the terms of the

Commons http://creativecommons.org/licenses/by-nc/4.0/, which permits reuse and

License redistribution, except for commercial purposes, provided that the original author and source are credited.

Email Alerting Receive free email alerts when new articles cite this article - sign up in Service the box at the top right corner of the article or click here. 